\title{
Research on Effects of Blast Casting Vibration and Vibration Absorption of Presplitting Blasting in Open Cast Mine
}

\author{
Li Ma, ${ }^{1,2}$ Kemin Li, ${ }^{2}$ Shuangshuang Xiao, ${ }^{2}$ Xiaohua Ding, ${ }^{2}$ and Sydney Chinyanta ${ }^{2}$ \\ ${ }^{1}$ State Key Laboratory for Geomechanics \& Deep Underground Engineering, China University of Mining and Technology, \\ Xuzhou, Jiangsu 221116, China \\ ${ }^{2}$ School of Mines, China University of Mining and Technology, Xuzhou, Jiangsu 221116, China \\ Correspondence should be addressed to Kemin Li; likemin513@126.com
}

Received 3 January 2016; Revised 16 June 2016; Accepted 29 June 2016

Academic Editor: Georges Kouroussis

Copyright (C) $2016 \mathrm{Li} \mathrm{Ma}$ et al. This is an open access article distributed under the Creative Commons Attribution License, which permits unrestricted use, distribution, and reproduction in any medium, provided the original work is properly cited.

\begin{abstract}
The impact energy produced by blast casting is able to break and cast rocks, yet the strong vibration effects caused at the same time would threaten the safety of mines. Based on the theory of Janbu's Limit Equilibrium Method (LEM), pseudo-static method has been incorporated to analyze the influence of dynamic loads of blasting on slope stability. The horizontal loads produced by blast vibrations cause an increase in sliding forces, and this leads to a lower slope stability coefficient. When the tensile stresses of the two adjacent blast holes are greater than the tensile strength of rock mass, the radical oriented cracks are formed, which is the precondition for the formation of presplit face. Thus, the formula for calculating the blast hole spacing of presplit blasting can be obtained. Based on the analysis of the principles of vibration tester and vibration pick-up in detecting blast vibrations, a detection scheme of blast vibration is worked out by taking the blast area with precrack rear and non-precrack side of the detection object. The detection and research results of blast vibration show that presplit blasting can reduce the attenuation coefficient of stress wave by half, and the vibration absorption ratio could reach $50.2 \%$; the impact of dynamic loads on the end-wall slope stability coefficient is $1.98 \%$, which proves that presplit blasting plays an important role in shock absorption of blast casting.
\end{abstract}

\section{Introduction}

Blasting operation, the initial step in open-pit mining, may break the ores into fragments so that they can be mined and loaded by excavating equipment. However, this operation might create environmental impacts such as air overpressure, ground vibration, fly-rocks, and back-break around the blasting zone [1-3]. Blast casting in open cast mines is usually associated with high bench, large hole diameter, and large explosive charge. More than 30\% stripping materials are cast into mined-out area, as a result, the operation of surplus overburdens in mining, loading, and hauling can be relatively reduced, resulting in a reduction in stripping costs and transportation costs. Based on the operation features of mining and loading equipment, the stripping technology composed of blast casting with dragline displays evident economic advantages among various mining technologies as blast casting is applied in rock breaking step. The shift and transportation of surplus material can be realized with the coordinated application of dragline stripping equipment. The total number of blast holes in a high bench blast casting can be more than 500. The explosive charge in one hole is between $1.8 \mathrm{t}$ and $2.7 \mathrm{t}$, and the aggregate explosive load reaches $900 \mathrm{t}$ to 1500 t. High bench blast casting may not only cause strong vibration effect and affect large area, but also exert severe influences on surrounding buildings and pit slope $[4,5]$. Consequently, controlling the vibration effects of blast casting and reducing the negative effects are of great importance to maintaining the regular production and work safety in open cast mines $[6,7]$.

The effective blast energy used for breaking and casting rocks only accounts for $20 \%$ to $30 \%$ of the gross energy, and the rest of the energy is distributed to producing flyrocks, causing vibration effect and dissipating into the air. Vibration velocity of rock mass particles is an important indicator for describing the intensity of vibration effect. Explosive volume, charge position, explosive type, detonation direction, and charge structure directly affect the vibration 
TABLE 1: Basic information of the minable coal seam.

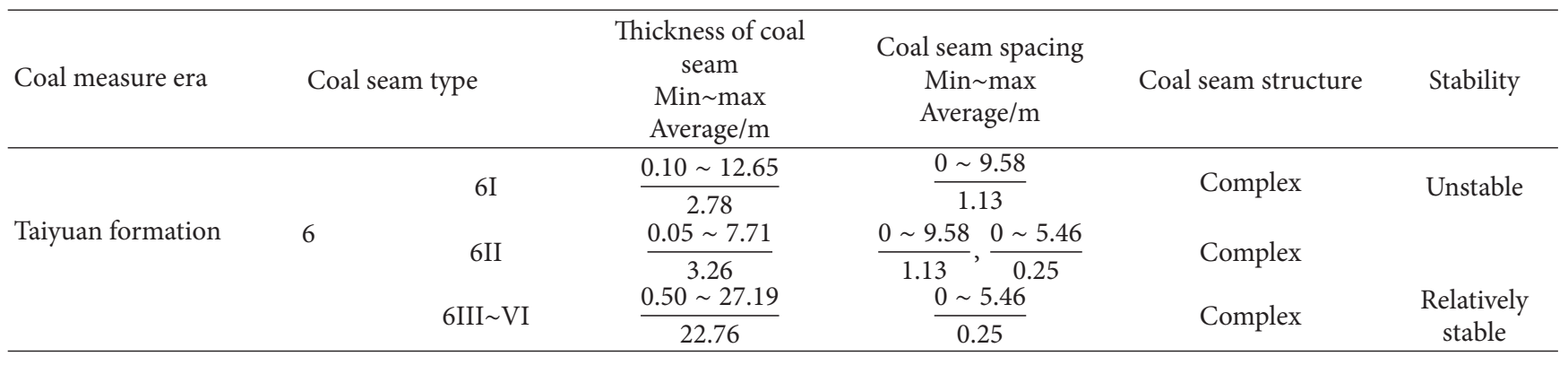

strength [8]. Therefore, millisecond blasting together with the detonation direction is often adopted to control the ignition charge over the same period. Presplit blasting is often used to control the blast vibration effect and mitigate disasters caused by vibrations. Changing the charge structure is also a conventional method [9-11], with which presplit blasting can exert positive effects on shock absorption and reduce detonation wave propagation since it is able to form presplit cracks with a definite width and depth before the detonation of the main blast hole. This leads to termination of the transmission of detonating waves. Presplit cracks cause reflection and refraction on stress waves causing the stress wave energy transmitted into rock mass within protection zones to be reduced $[12,13]$. Cai and Ma conducted a series of research on vibration reduction mechanism of presplit blasting with the application of joint stiffness model and stress wave theory. The research proved that the vibration absorption effect can be improved through increasing the length and depth of presplitting cracks [14]. Zou studied the vibration reduction result of presplit blasting with in situ investigation and figured out that the closer the presplit crack was, the better the vibration reduction results were obtained [15]. Salmi and Hosseinzadeh analyzed the mechanism of presplit blasting with the help of numerical simulation and determined that tensile stress waves induced by the denotation of two adjacent blast holes are the primary cause of presplit cracks [16]. Yang launched tests on trial blast holes with cross hole method and ultrasonic waves and established that presplit blasting might cause less damage to the rock mass in the slope than loosening blasting [17]. Sun et al. conducted some research on vibration effect of blast casting and its influences [18, 19]. Zhang and Song concluded and analyzed the practical experience of adopting presplitting blast in Heidaigou open cast mine and demonstrated that presplitting plays an important role in reducing blast vibration and maintaining the structure of rock mass in the slope $[20,21]$.

Presplit blasting is a major method to reducing the vibration effect of blast casting in higher bench and is of great significance to ensuring safety in blasting and production of open cast mines. Based on the characteristics of vibration effects and the vibration reduction mechanism of presplit blasting, the effects of presplit blasting on blast casting are analyzed on the basis of the study on the detection of results of blast vibration.

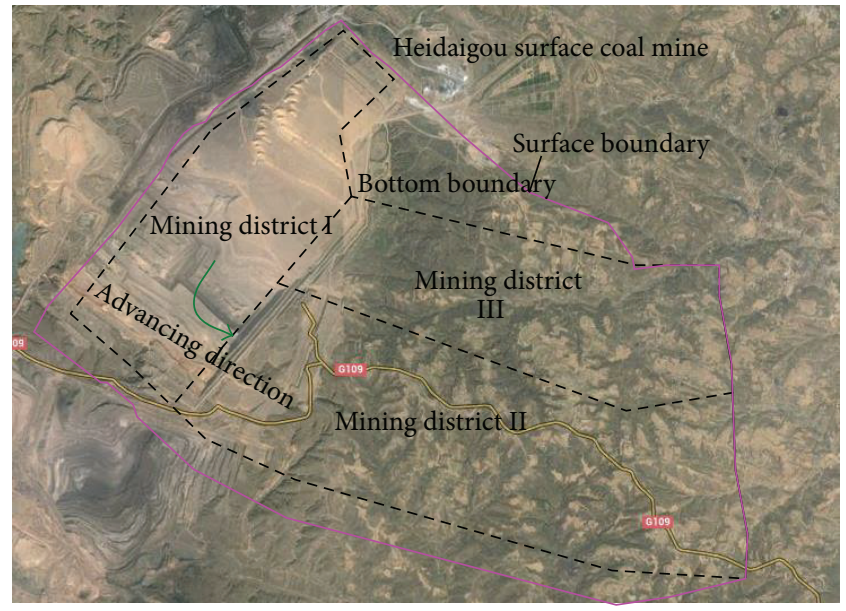

FIGURE 1: Mining district division and current exploitation status of Heidaigou open cast mine.

\section{Engineering Geology of the Experimental Area}

Heidaigou open cast mine is located in the southeastern part of Zhungeer Coalfield in Erdos Plateau. The average strike length of the mining range is $7.86 \mathrm{~km}$ and the width is $5.39 \mathrm{~km}$, resulting in a gross area of $42.36 \mathrm{~km}^{2}$. Most coals mined within this area are long flame coal with the characteristics of ultra-low-phosphorous, low-sulfur, and medium- or highash-fusion-point. The minable coal seam in Heidaigou is the 6th composite coal seam with thick-layer and massive structure; the average thickness is $28.8 \mathrm{~m}$ and dipping less than $10^{\circ}$. Table 1 shows the basic information of the minable coal seam. The aggregate amount of minable coals within the boundary reaches 149.77 million tons. The zone is divided into three mining districts. At present, it is in the transitional period from primary mining district to secondary mining district, as shown in Figure 1.

By adopting loosening blasting, the upper soil and rock of Heidaigou open cast are broken and fragmented into pieces to be excavated and loaded by shovels and then transported to an internal dump by self-discharging truck. With the application of blast casting in the rocks above the coal seam roof within the scope of $40 \sim 50 \mathrm{~m}$, more than $30 \%$ of the materials can be casted into the mined-out section and the surplus materials are disposed with a dragline. The strata of 
TABLE 2: Main characteristic parameters of rock stratum in the blasting area.

\begin{tabular}{lcccccc}
\hline Lithology & $\begin{array}{c}\text { Rock } \\
\text { density }(\gamma)\end{array}$ & $\begin{array}{c}\text { Rock mass } \\
\text { velocity }\left(v_{\mathrm{rm}}\right)\end{array}$ & $\begin{array}{c}\text { Rock wave } \\
\text { velocity }\left(v_{r}\right)\end{array}$ & $\begin{array}{c}\text { Integrity } \\
\text { coefficient } \\
\left(K_{i}\right)\end{array}$ & $\begin{array}{c}\text { Crack } \\
\text { coefficient } \\
\left(K_{c}\right)\end{array}$ & $\begin{array}{c}\text { Wave impedance } \\
(R)\end{array}$ \\
\hline Mudstone & $2.7 \mathrm{~g} / \mathrm{cm}^{3}$ & $1273 \mathrm{~m} / \mathrm{s}$ & $3744 \mathrm{~m} / \mathrm{s}$ & 0.12 & 0.88 & $3.44 \times 10^{3} \mathrm{~g} / \mathrm{cm}^{3} \cdot \mathrm{m} / \mathrm{s}$ \\
Sandstone & $2.3 \mathrm{~g} / \mathrm{cm}^{3}$ & $796 \sim 1118 \mathrm{~m} / \mathrm{s}$ & $1586 \sim 3226 \mathrm{~m} / \mathrm{s}$ & $0.06 \sim 0.5$ & $0.5 \sim 0.99$ & $2.2 \times 10^{3} \mathrm{~g} / \mathrm{cm}^{3} \cdot \mathrm{m} / \mathrm{s}$ \\
\hline
\end{tabular}

Note: the integrated coefficient of rocks is determined by the square of the ratio of rock mass velocity to rock wave velocity, $K_{i}=\left(v_{\mathrm{rm}} / v_{r}\right)^{2}$; the crack coefficient of rocks, $K_{c}=\left(V_{r}^{2}-V_{\mathrm{rm}}^{2}\right) / V_{r}^{2}$; the wave impedance of rocks, $R=\gamma \cdot v_{\mathrm{rm}}$.

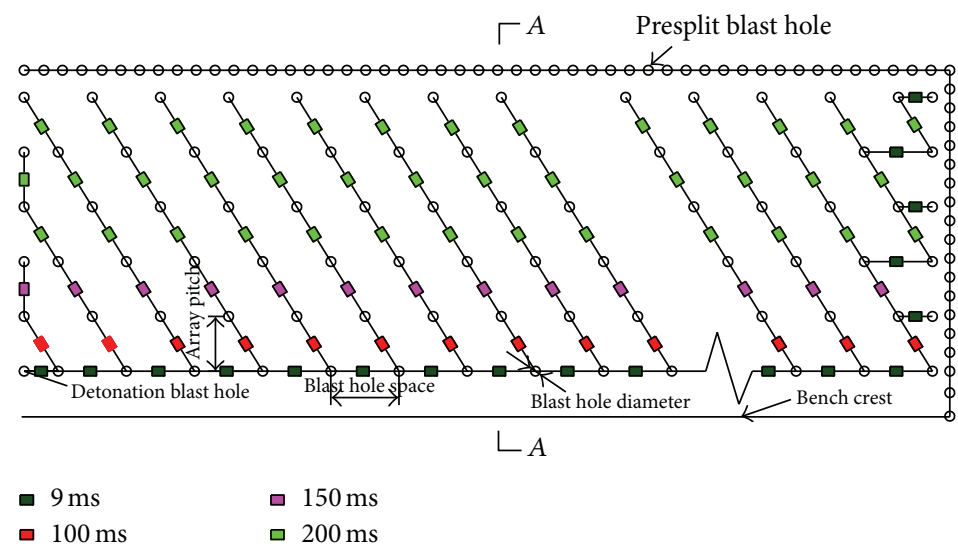

(a) Schematic diagram of the plane parameters and interconnected design of blast casting

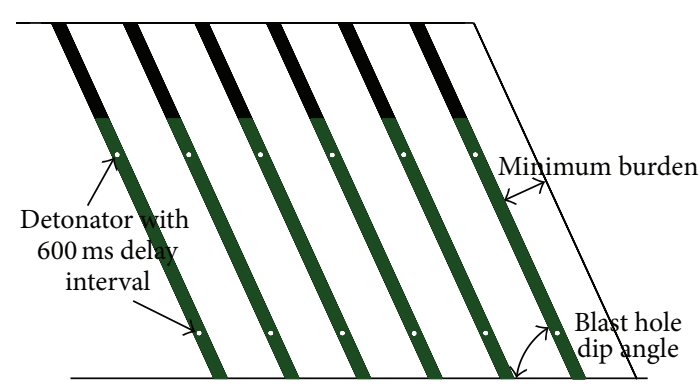

(b) Schematic diagram of the drilling parameters and explosive charge in blast casting

FIGURE 2: The schematic diagram of blast casting parameters.

the blast casting area are mainly composed of sandstone and mudstone, and the main characteristic parameters of rock strata are shown in Table 2 [22].

The blast hole diameter for blast casting in Heidaigou open cast is $310 \mathrm{~mm}$, the blast hole spacing is $9 \sim 12 \mathrm{~m}$, the array pitch is $7 \sim 9 \mathrm{~m}$, the plunge of blast hole ranges from $65^{\circ}$ to $70^{\circ}$, the unit explosive consumption is $0.7 \sim 0.9 \mathrm{~kg} / \mathrm{m}^{3}$, and the minimum burden is $6 \sim 6.5 \mathrm{~m}$. In order to control the detonation charge over the same period, hole-by-hole millisecond initiation control technology is adopted, the interhole delay is $9 \mathrm{~ms}$, the interarray delay is $100 \sim 200 \mathrm{~ms}$, and the time delay in holes is $600 \mathrm{~ms}$ [23]. Presplit blasting is adopted ahead of the detonation of main blast hole so that the impacts of blast vibrations on slope stability on high benches can be reduced. The result is commendable, as shown in Figure 2.

\section{Vibration Effects of Blast Casting and Vibration Absorption Mechanism of Presplit Blasting}

3.1. Vibration Effect of Blast Casting and Its Impact on Slope Stability. The displacement, velocity, and acceleration of particle motion caused by blasts are three factors for describing blast vibration strength. Moreover, since the critical safety values of acceleration and displacement are within a relatively wide limit, velocity of blast vibration naturally becomes the most important parameter for determining the destruction-bearing capacity of the medium. According to
Sadov's empirical formula, the velocity of blast vibration can be determined as [24]

$$
\begin{aligned}
v & =\frac{k}{\sqrt[3]{f(n)}}\left(\frac{\sqrt[3]{Q}}{R}\right)^{\alpha}, \\
f(n) & =0.4+0.6 n^{3},
\end{aligned}
$$

where $v$ is the velocity of blasting vibration, $\mathrm{cm} / \mathrm{s}$; $Q$ is the maximum explosive charge ignited over the same period, $\mathrm{kg}$; $R$ is the distance between blasting source center and guard point, $\mathrm{m} ; \alpha$ is attenuation coefficient of seismic wave related to geological conditions, $\alpha=1$ to 3 ; $k$ is medium parameter related to rock properties and blasting methods, $k=50 \sim 200$; $f(n)$ is the exponential function of the blasting effect; $n$ is the index of the blasting effect.

According to wave theory, it can be assumed that blasting seismic wave is composed of several simple harmonic waves with different amplitudes and different vibration frequencies [25]:

$$
\begin{aligned}
X & =\sum_{i} A_{i} \sin \left(\omega_{i} t\right), \\
V & =\sum_{i} \omega_{i} A_{i} \cos \left(\omega_{i} t+\varphi_{i 1}\right), \\
a & =\sum_{i} \omega_{i}^{2} A_{i} \sin \left(\omega_{i} t+\varphi_{i 1}\right),
\end{aligned}
$$

where $X$ is displacement, $\mathrm{cm} ; V$ is vibration velocity, $\mathrm{cm} / \mathrm{s}$; $a$ is vibration acceleration, $\mathrm{cm} / \mathrm{s}^{2} ; A_{i}$ is blasting vibration 


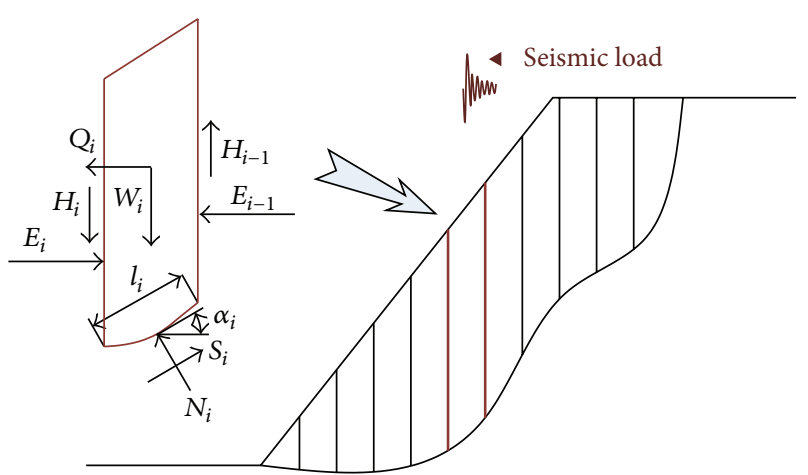

FIGURE 3: Force diagram on noncircular slip surface with slices based on Janbu Method.

amplitude, $\mathrm{cm} ; \omega_{i}$ is circular frequency, $\omega=2 \pi f, \mathrm{~Hz} ; t$ is time, $s ; \varphi_{i 1}$ and $\varphi_{i 2}$ denote phase differences.

High bench is applied in blast casting with the blast parameters of deep and large blast hole diameter. The rock volume blasted each time and the explosive consumption is huge. Blast vibration effect is a significant factor affecting slope stability of open cast mines. When calculating slope stability affected by blasting dynamics with pseudo-static method, it is usually assumed that the horizontal loads of blasting vibration exerted on the slope slip mass are equivalent to static loads [26]:

$$
\begin{aligned}
& Q_{i}=K_{s} W_{i}, \\
& K_{s}=\frac{K_{D} a_{i}}{g},
\end{aligned}
$$

$$
F_{s}=\frac{\sum\left(\sec ^{2} \alpha_{i} /\left(1+\tan \alpha_{i} \tan \varphi_{i} / F_{s}\right)\right)\left[c_{i} l_{i} \cos \alpha_{i}+\left(W_{i}+H_{i}-H_{i-1}\right) \tan \varphi_{i}\right]}{\sum\left(W_{i}+H_{i}-H_{i-1}\right) \tan \alpha_{i}+\sum Q_{i} \cos \alpha_{i}}
$$

where $E_{i-1}$ and $E_{i}$ are the normal forces of the $i$ th slice; $H_{i-1}$ and $H_{i}$ are the vertical shear stresses of the $i$ th slice; $N_{i}$ and $S_{i}$ are the vertical reactions and shear forces on the slipping surface, respectively; $l_{i}$ is the slice's bottom length of the sliding surface of the $i$ th slice; $c_{i}$ is cohesive force of the $i$ th slice; $\varphi_{i}$ is the internal angle of friction of the $i$ th slice; $F_{s}$ is the factor of safety.

It can be seen from Figure 3 and (7) that the horizontal load produced by blast vibration on the slip mass and the sliding component caused by gravity together constitute the sliding force of the slip mass. The factor of safety of the slope that has been affected by blast vibration is reduced compared to rock masses that are not affected.

\subsection{Vibration Absorption Mechanism of Presplit Blasting.} Blast casting in high bench of open cast mines causes the production of large blasting volume and devastating shock; it can cause relatively severe effects on slope stability of adjacent rock masses which have not been blasted. But as a special method for blasting control, presplit blasting can be very effective in reducing blast vibrations. This is achieved by where $Q_{i}$ is the equivalent static load, $\mathrm{N} ; K_{s}$ is seismic load coefficient; $a_{i}$ is vibration acceleration, $\mathrm{m} / \mathrm{s}^{2} ; W_{i}$ is the slice weight of sliding mass, $\mathrm{N} ; \mathrm{g}$ is gravitational acceleration, $\mathrm{m} / \mathrm{s}^{2}$; $K_{D}$ is reduction coefficient of blasting dynamics whose value range is $0.008 \sim 0.152$.

According to the schematic diagram for noncircular slip surface shown in Figure 3, the following equation based on Janbu's theory and the equilibrium condition of slice can be obtained [27]:

$$
\begin{aligned}
\sum Y & =0 \\
W_{i}+H_{i}-H_{i-1}-N_{i} \cos \alpha_{i}-S_{i} \sin \alpha_{i} & =0 \\
\sum X & =0 \\
E_{i}-E_{i-1}+S_{i} \cos \alpha_{i}-N_{i} \sin \alpha_{i}-Q_{i} & =0
\end{aligned}
$$

According to Mohr's-Coulomb criterion, the shear force on the bottom sliding surface should meet the following condition:

$$
S_{i}=\frac{c l_{i}}{F_{s}}+N_{i} \frac{\tan \varphi}{F_{s}}
$$

Based on the balance of forces of the whole landslide,

$$
\sum\left(W_{i}+H_{i}-H_{i-1}\right) \tan \alpha_{i}-\sum S_{i} \sec \alpha_{i}+\sum Q_{i}=0
$$

Combining (4), (5), and (6), the following factor of safety equation is obtained: detonating the explosive charge placed in the presplit hole of the main blasting area and then separating the rock masses from original ones after cracks are formed along the blasting area boundary. In this way, the damages caused by blast vibrations on the original rock masses can be reduced.

The necessary condition to ensure the success of presplit blasting is that the pressure of the explosion in the blast holes will not damage the wall of the hole and the presplit crack will develop along the predetermined direction. According to stress wave interference theory [28-30], stress waves of each explosion spread radically after the denotation of two adjacent presplit holes as shown in Figure 4.

After the charge is denoted, the peak of the stress wave front weakens as the propagation distance of the stress wave increases with the attenuation formula $[31,32]$ :

$$
\begin{aligned}
& P_{R}=P_{D}\left(\frac{r_{1}}{R}\right)^{\alpha}, \\
& P_{D}=\frac{1}{k+1} \rho D^{2}\left(\frac{r_{1}}{r_{2}}\right)^{-2 k} n,
\end{aligned}
$$




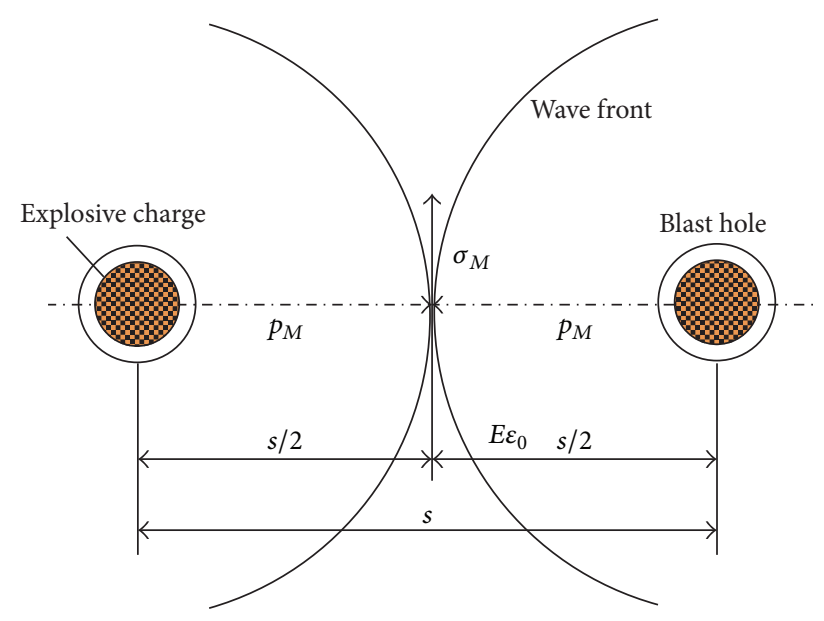

FIGURE 4: Wave front of two adjacent blast holes.

where $P_{R}$ is the pressure of stress wave front after the detonation of explosive charge, $\mathrm{Pa} ; r_{1}$ is the radius of blast hole, $\mathrm{m} ; R$ is the distance between the center of blast hole and a certain point on the wave front, $\mathrm{m} ; \alpha$ is the attenuation coefficient, $\alpha=2-\mu /(1-\mu) ; \mu$ is Poisson's ratio; $P_{D}$ is the pressure on the wall of the holes, $\mathrm{Pa} ; \rho$ is explosive density, $\mathrm{kg} / \mathrm{m}^{3} ; D$ is explosive speed, $\mathrm{m} / \mathrm{s} ; r_{2}$ is the radius of explosive, $\mathrm{m}$; $k$ is adiabatic exponent; $n$ is the multiple of pressure increase of the explosive gas colliding with the blast hole wall, and $n=8 \sim 11$.

The stress wave causes radical displacement of the rock mass between two adjacent blast holes, while the radical displacement derives the tangential stresses and tangential strains. The tangential stress $\sigma_{T}$ can be expressed as [33]

$$
\sigma_{T}=\frac{\mu}{1-\mu} P_{R}
$$

If the tangential stress on the wall of the hole is greater than the rock tensile strength $\sigma_{t}$, the initial crack on the wall of the blast hole will appear. Resulting from the stress wave of two adjacent blast holes, the sum $\sigma_{M}$ of the tangential stress in the middle of the line connecting the two adjacent blast holes $(R=s / 2)$ is

$$
\sigma_{M}=\frac{2 \mu}{(1-\mu)(k+1)} \rho D^{2}\left(\frac{r_{1}}{r_{2}}\right)^{-2 k} n\left(\frac{2 r_{1}}{s}\right)^{\alpha} .
$$

Similarly, if the tensile stress produced by blasting $\sigma_{M}$ is greater than the tensile strength of rocks, that is, $\sigma_{M} \geq \sigma_{t}$, radial cracks appear along the lines connecting blast holes, which creates condition for the formation of the presplit face. The high pressure gas of explosion of the two adjacent blast holes then acts on the walls of the hole, thereby forming a quasi-static stress field around the blast holes. When the high pressure gas wedges in the initial crack of hole wall, there is a great tensile stress along the line connecting blast holes. The tensile stress concentration is all sides of the walls of the hole. A free surface with a certain width is formed which can exert positive effects towards the reduction in vibrations.
Therefore, the important precondition for the formation of the presplit face is that tension waves can produce tension crack. Based on (10), the formula of the blast hole spacing in presplit blasting should be

$$
s \leq \frac{2 r_{1}}{\left[\sigma_{t}\left((1-\mu)(k+1) / 2 \mu \rho D^{2} n\right)\left(r_{1} / r_{2}\right)^{2 k}\right]^{1 / \alpha}} .
$$

Low density ANFO explosive is used as a presplit blast explosive in Heidaigou open cast with a density of $200 \mathrm{~kg} / \mathrm{m}^{3}$, a speed of $1950 \mathrm{~m} / \mathrm{s}$, a presplit blast hole diameter of $310 \mathrm{~mm}$, charge diameter of $150 \mathrm{~mm}$, and a unit explosive consumption of $0.85 \mathrm{~kg} / \mathrm{m}^{3}$. According to (11), the optimum blast hole spacing of presplit blasting is estimated as ranging from $3.03 \mathrm{~m}$ to $4.16 \mathrm{~m}$, with $3.5 \mathrm{~m}$ selected for application. Figure 5 shows the presplit blasting effect. The cracks formed from the blast are relatively intact with an even width and the ratio of the half hole to the total presplit hole is a little higher.

The transmission coefficient of stress wave is

$$
R_{t}=\frac{A_{t}}{A_{i}}
$$

where $R_{t}$ is the transmission coefficient and $A_{i}$ and $A_{t}$ are the amplitude of incident wave and the amplitude of transmitted wave, respectively.

The wave velocity expression is

$$
v=A e^{-\alpha} \sin \omega t
$$

and the vibration absorption ratio of presplit blasting is

$$
\varepsilon=\frac{\left|v_{i}\right|_{\max }-\left|v_{t}\right|_{\max }}{\left|v_{i}\right|_{\max }}=\frac{\left|A_{i}\right|_{\max }-\left|A_{t}\right|_{\max }}{\left|A_{i}\right|_{\max }}=1-R_{t} .
$$

\section{Detection and Analysis of Vibration Produced by Blast Casting}

4.1. The Detection Principles of Blast Vibration. Detection system of blast vibration is composed of the blast vibration tester and the vibration pick-up. As the vibration wave is transmitted to the vibration pick-up, induced voltage outputs are generated and once the induced voltage signal exceeds the preset triggering level, the tester automatically records and saves the vibration signals loaded by the sensor. After detecting the vibration signals, the blast vibration waves can be read and analyzed with the connection and communication between special software and vibration tester. The principle diagrams of the detection system and the measuring point layout are shown in Figures 6 and 7, respectively.

Based on the inspection data, the regression analysis should be carried out with Sadov's empirical formula and the formula of vibration velocity attenuation can thus be obtained.

4.2. Detection Scheme of Blast Vibration. In order to record the whole vibration process and the attenuation law of blasting seismic waves, the detection scheme of blast vibration is 

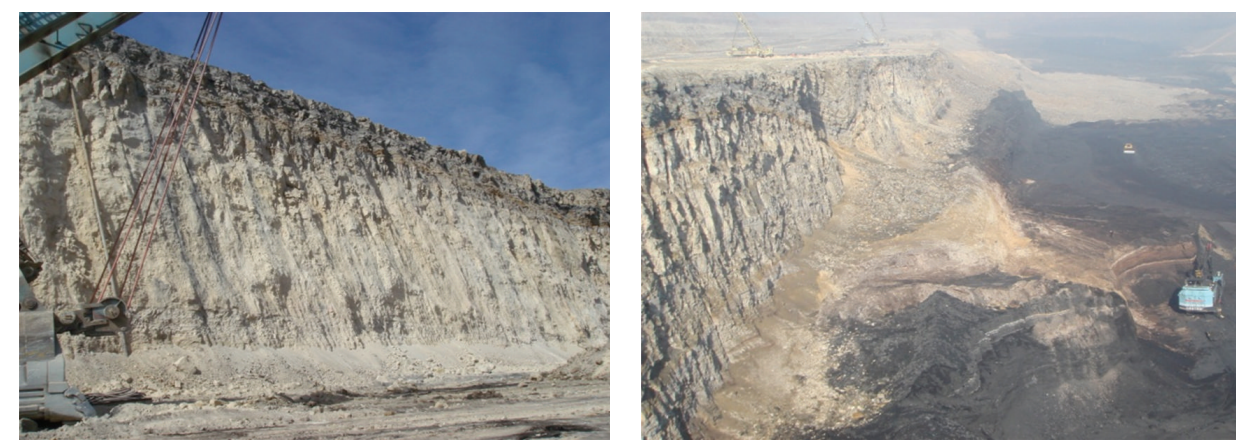

FIgURE 5: Presplit blasting effect pictures of surface coal mine.

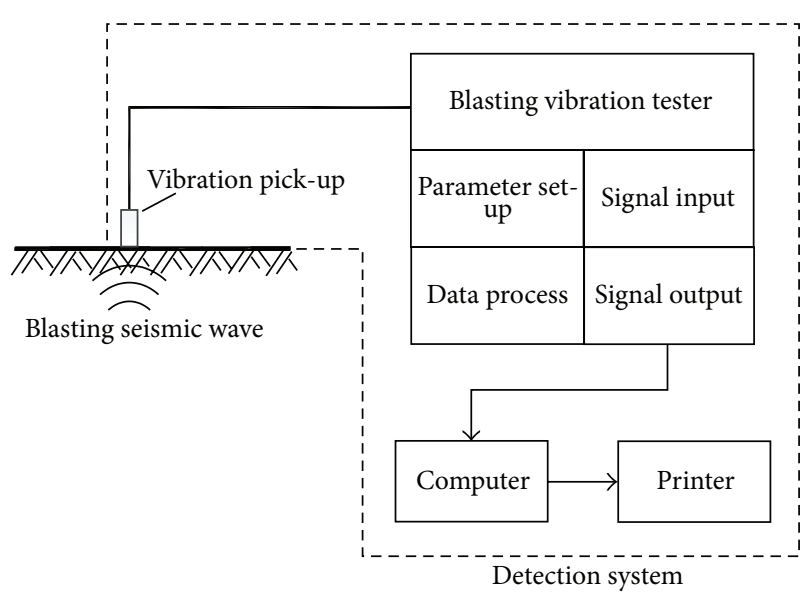

FIGURE 6: The principle diagram of the detection system.

worked out according to the characteristics of blast casting and the geological and topographic conditions of the blasting zone. Detection points are set on the same bench and kept in a straight line on the right side of the blasting zone without presplit blast. Another set of detection points are also set on the same bench in a straight line on the rear blasting zone with presplit blast. Both of the above-mentioned detection points are used to monitor the seismic intensity and variations of blast vibrations.

The blast vibration tester adopted here is a vibration signal recorder whose model is UBOX-20016, the maximum sampling rate of which is $200 \mathrm{KSps} / \mathrm{CH}$ and the signal resolution is 16 bits (1/65536 of the measuring range). The vibration pick-up is $\mathrm{CD}-21$ magnetoelectric vibration velocity sensor with the sensitivity of $200 \mathrm{mv} / \mathrm{cm} / \mathrm{s}$, and the error is less than $3 \%$. The installation of sensors is based on the measurement of vibration velocity in different directions and the censors must be firmly bonded to the ground by gypsum powder.

The primary detection area of blast vibration is the rear part and the broadside of the blasting zone: the former is with presplit cracks and the latter is without. Therefore, the effect of presplit cracks in vibration reduction can be proved by comparison. Blast vibration recorder is used for inspecting the velocity of particles in vertical direction $(\mathrm{V}-)$, radial direction (R-), and transverse direction (T-). Figure 8 shows the schematic diagram of detection point layout.

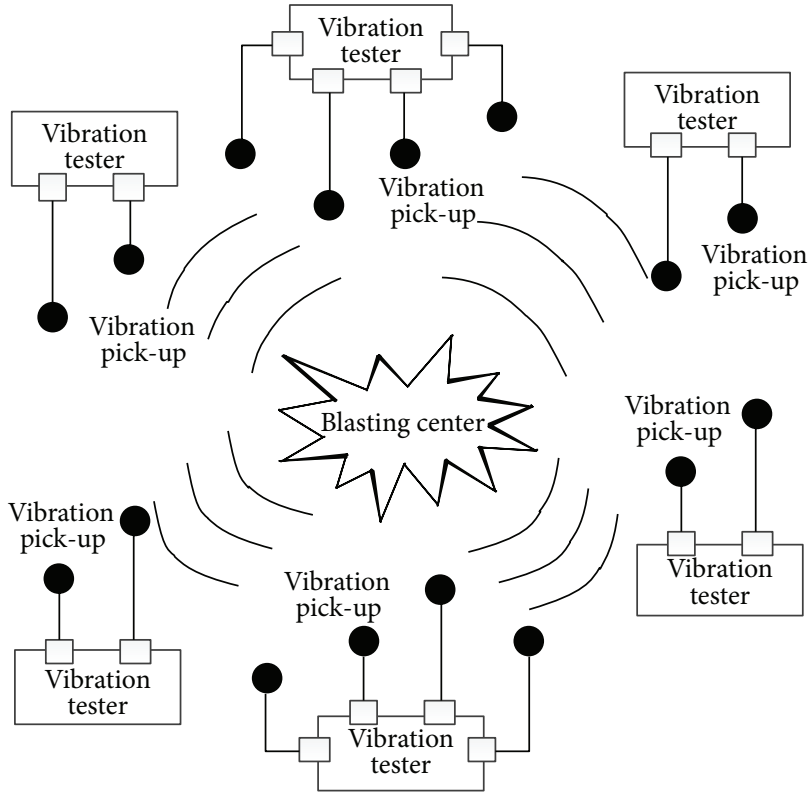

FIGURE 7: The schematic diagram of the measuring point layout.

4.3. Analysis on the Detection Results of Blasting Vibration. In all cases, blast vibration detection has been carried out three (3) times. The gross explosive loads (GEL) for each time are $9.6 \times 10^{5} \mathrm{~kg}, 7.8 \times 10^{5} \mathrm{~kg}$, and $1.3 \times 10^{6} \mathrm{~kg}$, respectively. The maximum explosive charges per delay interval (MECPDE) are $1 \times 10^{4} \mathrm{~kg}, 1.5 \times 10^{4} \mathrm{~kg}$, and $1.5 \times 10^{4} \mathrm{~kg}$, respectively, and the explosive charge per blast hole is $2 \times 10^{3} \mathrm{~kg}$. The distance between each detection point and the blasting source (DDPBS) as well as the vibration velocity of the largest particle are shown in Table 3.

Standard blast casting is adopted in Heidaigou open cast, and the blasting acting index $n=1$. Based on (1) and the detection data, the attenuation equations for blast vibration in presplit blasting and non-presplit blasting are obtained by fitting:

$$
= \begin{cases}95.18\left(\frac{\sqrt[3]{Q}}{R}\right)^{1.34}, & R^{2}=0.959 \text { (presplit blast) } \\ 221.61\left(\frac{\sqrt[3]{Q}}{R}\right)^{1.40}, & R^{2}=0.795 \text { (non-presplit blast). }\end{cases}
$$


TABLE 3: Location of detection points and blast vibration strength.

\begin{tabular}{|c|c|c|c|c|c|c|c|c|}
\hline Detection point & $T-\mathrm{mm} / \mathrm{s}$ & $V-\mathrm{mm} / \mathrm{s}$ & $R-\mathrm{mm} / \mathrm{s}$ & Resultant $\mathrm{mm} / \mathrm{s}$ & DDPBS m & GEL kg & MECPDE kg & Remarks \\
\hline H1-2 & 14.1 & 11.1 & 10.8 & 17.4 & 350 & 960000 & 10000 & Back \\
\hline $\mathrm{H} 1-3$ & 10.4 & 16.8 & 7.8 & 17.9 & 550 & 960000 & 10000 & Back \\
\hline $\mathrm{H} 1-4$ & & 4.3 & 9.9 & 10 & 800 & 960000 & 10000 & Back \\
\hline $\mathrm{H} 1-5$ & 1.7 & 2.3 & 3.8 & 3.9 & 1215 & 960000 & 10000 & Back \\
\hline H1-6 & 1.1 & 1.9 & 2.8 & 2.9 & 1800 & 960000 & 10000 & Back \\
\hline $\mathrm{H} 2-1$ & 104.7 & 149.7 & 124.3 & 181.3 & 100 & 780000 & 15000 & Back \\
\hline $\mathrm{H} 2-2$ & 31.7 & 56.5 & 32.7 & 55 & 200 & 780000 & 15000 & Back \\
\hline $\mathrm{H} 2-3$ & 11.8 & 17.3 & 16.3 & 20.4 & 300 & 780000 & 15000 & Back \\
\hline $\mathrm{H} 2-4$ & 10.8 & 13.9 & & 18.7 & 500 & 780000 & 15000 & Back \\
\hline $\mathrm{H} 2-5$ & 4.5 & 3.9 & 3.7 & 7.9 & 800 & 780000 & 15000 & Back \\
\hline $\mathrm{H} 2-6$ & 4.2 & 2.5 & 2.3 & 5.4 & 1000 & 780000 & 15000 & Back \\
\hline $\mathrm{H} 2-7$ & 17.4 & 30 & 22 & 41.1 & 380 & 780000 & 15000 & Back \\
\hline H3-1 & 66.7 & 69.4 & 59.8 & 87.4 & 162 & 1300000 & 15000 & Back \\
\hline Y1-1 & 28.6 & 13.5 & 29.1 & 30.3 & 574.9 & 960000 & 10000 & Right \\
\hline Y1-2 & 19.6 & 12.1 & 30.6 & 31.1 & 604.6 & 960000 & 10000 & Right \\
\hline Y1-3 & 12.6 & 5.59 & 12.4 & 14.5 & 800 & 960000 & 10000 & Right \\
\hline Y1-4 & 8.51 & 3.05 & 8.51 & 10.3 & 826.6 & 960000 & 10000 & Right \\
\hline Y3-1 & 65.6 & 70.9 & 70.8 & 118 & 200 & 1300000 & 15000 & Right \\
\hline Y3-2 & 23.3 & 28 & 25.5 & 50.7 & 350 & 1300000 & 15000 & Right \\
\hline Y3-4 & 10.1 & 5.8 & - & 17.5 & 550 & 1300000 & 15000 & Right \\
\hline Y3-5 & 6.5 & 2.4 & 3.7 & 10.7 & 650 & 1300000 & 15000 & Right \\
\hline
\end{tabular}

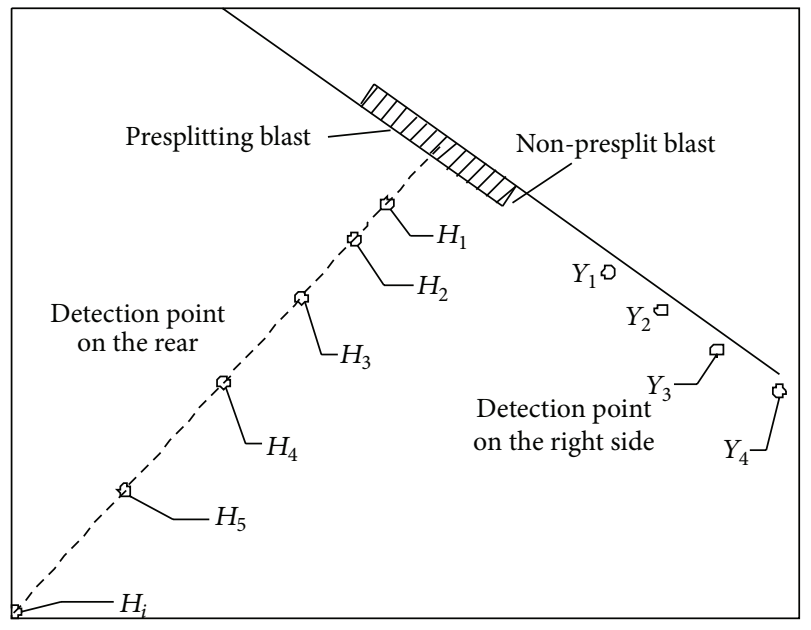

FIGURE 8: Location of the blast detection point and blast vibration source.

According to (15), the attenuation indices under these two conditions are nearly the same, that is, 1.34 and 1.40 , respectively. However, the attenuation coefficient might be reduced by half when adopting presplit blasting. Because of the application of hole-by-hole millisecond detonation, the maximum explosive charge per segment is less than 1.1 $\times 10^{4} \mathrm{~kg}$, and the vibration velocity of the end-wall slope is $2.53 \mathrm{~cm} / \mathrm{s}$. In addition, the equation for calculating the acceleration of blast vibration is [34]

$$
a=0.028 Q^{0.83} R^{-3.5} C_{p}{ }^{2},
$$

where $a$ is acceleration of the blast vibration, $\mathrm{m} / \mathrm{s}^{2} ; C_{p}$ is the longitudinal wave velocity, $\mathrm{m} / \mathrm{s}$; other symbols are consistent with the former expressions.

The transmission velocity of blast vibration in sandstone rock mass is $1118 \mathrm{~m} / \mathrm{s}$, the acceleration is calculated as $1.21 \mathrm{~m} / \mathrm{s}^{2}$ (16), and the seismic load coefficient of blasting is calculated as 0.012 (3). According to the mechanical parameters of rock mass of Heidaigou open cast listed in Table 4, the factors of stability of the end-wall slope are calculated as 1.311 for the condition of static load and 1.285 for the condition of dynamic load, respectively. Therefore, the effect of dynamic load on factor of safety of the end wall is merely $1.98 \%$.

Meanwhile, the resultant vibration velocities of different detection points are shown in Table 5. As the distance between detection points and blasting centers increases, the vibration velocities decrease exponentially under the condition of both presplit blasting and non-presplit blasting. A closer distance to the blasting center can better reflect the vibration reduction effect of presplit blasting. When the detection point is $200 \mathrm{~m}$ away from the blasting center, the vibration absorption ratio is increased to $50.2 \%$, which implies that presplit blasting can effectively absorb vibrations.

\section{Conclusions}

(1) Pseudo-static method has converted the dynamic load of blast vibration to equivalent static load, and Janbu LEM has been used to analyze the influence of blast vibration on slope stability. The horizontal load caused by blast vibration enhances the sliding force of the slip mass and therefore 
TABLE 4: Mechanical parameters of rock mass of Heidaigou open cast.

\begin{tabular}{lccc}
\hline Stratum & Density $\left(\mathrm{kN} / \mathrm{m}^{3}\right)$ & Internal friction angle $\left(^{\circ}\right)$ & Cohesion $(\mathrm{kPa})$ \\
\hline Loess & 19.50 & 29.5 & 45.1 \\
Sandy mudstone & 24.50 & 30 & 135 \\
Fine sandstone & 24.50 & 28 & 150 \\
Medium sandstone & 22.70 & 31.5 & 150 \\
Coarse sandstone & 22.40 & 32.0 & 130 \\
Weathered mudstone & 24.7 & 29.0 & 127.5 \\
Coal & 14 & 35 & 185.1 \\
Siltstone & 24.5 & 31.3 & 176.8 \\
\hline
\end{tabular}

TABLE 5: Actual blast vibration detection data and absorption shock rate of presplit blasting.

\begin{tabular}{|c|c|c|c|c|c|c|c|}
\hline \multirow{2}{*}{$\begin{array}{l}\text { Detection point distance to } \\
\text { blasting center/m }\end{array}$} & \multicolumn{7}{|c|}{ Velocity of vibration $/ \mathrm{cm} \cdot \mathrm{s}^{-1}$} \\
\hline & 200 & 400 & 600 & 800 & 1000 & 1200 & 1400 \\
\hline Presplit blasting & 5.48 & 2.21 & 1.3 & 0.89 & 0.66 & 0.52 & 0.43 \\
\hline Non-presplit blasting & 11.01 & 3.97 & 2.18 & 1.43 & 1.03 & 0.79 & 0.63 \\
\hline Vibration reduction ratio & $50.2 \%$ & $44.3 \%$ & $40.4 \%$ & $37.8 \%$ & $35.9 \%$ & $34.2 \%$ & $31.7 \%$ \\
\hline
\end{tabular}

reduces the factor of safety. Calculated results suggest that slope stability factors on conditions of static load and dynamic load of blasting are 1.311 and 1.285 , respectively, and the dynamic load of blast casting has slight effect on the end slope stability, taking only $1.98 \%$.

(2) After the detonation of two adjacent presplit holes, stress waves of each explosion spread radially and create tangential stress in the tangential direction. Based on the theory of stress wave interference, when the sum of the tangential stress of two adjacent blast holes is greater than the rock tensile strength, radial cracks come into being along the line connecting blast holes, which creates condition for the formation of the presplit face. Based on the above condition, the blast hole spacing in presplit blasting is obtained. Accordingly, the blast hole spacing of presplit blasting of Heidaigou open cast mine ranges from $3.03 \mathrm{~m}$ to $4.16 \mathrm{~m}$, with $3.5 \mathrm{~m}$ used in actual production, satisfying the presplit blasting effect.

(3) The vibration detection principles of vibration testers and pick-ups are analyzed. The vibration velocity of blasting particle is detected in the blasting zone whose rear part is with presplit cracks, and right side is without. Based on Sadov's empirical formula, attenuation formulas of blast vibration on conditions with and without presplit blasting are obtained by numerical fitting, respectively. The detection results indicate that presplit blasting can reduce the attenuation coefficient by half, and the vibration absorption ratio can reach $50.2 \%$, which means presplitting blast is of great significance in shock absorption of blast casting.

\section{Competing Interests}

The authors declare that there are no competing interests regarding the publication of this paper.

\section{Acknowledgments}

This study was supported by the National Natural Science Foundation of China (51034005), the Fundamental
Research Funds for the Central Universities (2010QNB23, 2011QNB25), and the Priority Academic Program Development of Jiangsu Higher Education Institutions.

\section{References}

[1] K. Pathak, S. Durucan, and S. Kunimatsu, "Activity accounting technique for environmental noise assessment in mechanized surface mining," Environmental Monitoring and Assessment, vol. 56, no. 3, pp. 241-256, 1999.

[2] A. Fişne, C. Kuzu, and T. Hüdaverdi, "Prediction of environmental impacts of quarry blasting operation using fuzzy logic," Environmental Monitoring and Assessment, vol. 174, no. 1-4, pp. 461-470, 2011.

[3] D. J. Armaghani, E. Momeni, S. V. A. N. K. Abad, and M. Khandelwal, "Feasibility of ANFIS model for prediction of ground vibrations resulting from quarry blasting," Environmental Earth Sciences, vol. 74, no. 4, pp. 2845-2860, 2015.

[4] T. N. Singh and V. Singh, "An intelligent approach to prediction and control ground vibration in mines," Geotechnical and Geological Engineering, vol. 23, no. 3, pp. 249-262, 2005.

[5] U. Ozer, A. Kahriman, M. Aksoy, D. Adiguzel, and A. Karadogan, "The analysis of ground vibrations induced by bench blasting at Akyol quarry and practical blasting charts," Environmental Geology, vol. 54, no. 4, pp. 737-743, 2008.

[6] C. Kuzu and E. Guclu, "The problem of human response to blast induced vibrations in tunnel construction and mitigation of vibration effects using cautious blasting in half-face blasting rounds," Tunnelling and Underground Space Technology, vol. 24, no. 1, pp. 53-61, 2009.

[7] D. D. Li and Z. D. Deng, "Evaluation of the effects of blasting vibration on humans in the excavation of CMICT dock," Engineering Blasting, vol. 12, no. 2, pp. 82-85, 2012.

[8] F. Zheng, W. D. Duan, D. W. Zhong, and B. Y. Sun, "Research progress and existing problems of blasting vibration," Blasting, vol. 23, no. 1, pp. 92-94, 2006.

[9] T. L. Shi and B. Z. Li, "The effects of millisecond delay interval, charge distribution and measuring distance on blasting vibration," Engineering Blasting, vol. 9, no. 4, pp. 10-13, 2003. 
[10] Y. L. Gao, Q. Tan, S. C. Yang, L. Xue, and Y. L. Yu, "Experimental research on relationship between charge layout and blasting vibration," Engineering Blasting, vol. 10, no. 3, pp. 19-48, 2004.

[11] Ö. Uysal and M. Cavus, "Effect of a pre-split plane on the frequencies of blast induced ground vibrations," Acta Montanistica Slovaca, vol. 18, no. 2, pp. 101-109, 2013.

[12] J. L. Yan and X. F. Chen, "Observation and analysis of vibration reduction effect of pre-split crack in complicated geologic condition," Blasting, vol. 25, no. 3, pp. 100-102, 2008.

[13] A. J. Prakash, P. Palroy, and D. D. Misra, "Analysis of blast vibration characteristics across a trench and a pre-split plane," Fragblast, vol. 8, no. 1, pp. 51-60, 2004.

[14] L. J. Cai and J. J. Ma, "The shock absorption mechanism and its effect analysis of pre-splitting blasting," China Mining Magazine, vol. 14, no. 5, pp. 56-58, 2005.

[15] Y. F. Zou, "Experimental study on the vibration- isolating effect of pre-split crack and vibration-isolating slot," Blasting, vol. 22, no. 2, pp. 96-99, 2005.

[16] E. F. Salmi and S. Hosseinzadeh, "A further study on the mechanism of pre-splitting in mining engineering," Applied Mechanics and Materials, vol. 553, pp. 476-481, 2014.

[17] N. H. Yang, "Experimental study on rock damage in the slope caused by presplit blasting," Journal of the China Railway Society, vol. 30, no. 3, pp. 96-99, 2008.

[18] H. R. Sun, Y. J. Tong, X. L. Lin, and H. S. Gao, "Study on the Vibration Effect of sling blasting in an open coal mine," Blasting, vol. 25, no. 1, pp. 69-73, 2008.

[19] Q. K. Chen, G. C. Li, and K. M. Li, "Monitor and analysis on explosive seismic effect of high-bench cast blast of surface coal mine," Explosive Materials, vol. 37, no. 6, pp. 30-33, 2008.

[20] P. K. Zhang and F. G. Song, "Pre-splitting blasting applied in high-bench cast blasting," Opencast Mining Technology, no. 1, pp. 35-41, 2007.

[21] P. K. Zhang, "Application of pre-splitting blasting in high-bench cast blasting of Heidaigou open pit," Inner Mongolia Science Technology \& Economy, no. 6, pp. 257-258, 2008.

[22] W. M. Hu, "Black dai ditch open-pit coal mine rock wave velocity testing technology," Journal of North China Institute of Science and Technology, vol. 11, no. 9, pp. 63-67, 2014.

[23] X. H. Ding, K. M. Li, S. S. Xiao, and W. M. Hu, "Analysis of key technologies and development of integrated digital processing system for cast blasting design," Journal of Central South University, vol. 22, no. 3, pp. 1037-1044, 2015.

[24] C. G. Jin, "Vibrating effect of blasting in open-pit slope," Metal Mine, no. 5, pp. 18-20, 1995.

[25] Q. Liu and S. R. Lv, "Research on the millisecond delay interval time of open-pit bench blasting," Engineering Blasting, vol. 20, no. 1, pp. 54-58, 2014.

[26] M. Chen, W. Lu, D. Shu, and C. Zhou, "Calculation method of equivalent acceleration for limit equilibrium analysis of slope under blasting vibration," Chinese Journal of Rock Mechanics and Engineering, vol. 28, no. 4, pp. 784-790, 2009.

[27] B. He and Y. Wang, "Residual thrust method and Janbu method used to calculate landslide stability," Safety and Environmental Engineering, vol. 11, no. 4, pp. 60-62, 2004.

[28] Y. L. Yu, Theory and Technology of Engineering Blasting, Metallurgical Industry Press, Beijing, China, 2004.

[29] W. M. Ling, "A study on the fracture mechanism of smooth blasting and pre-split blasting," Journal of China University of Mining \& Technology, vol. 19, no. 4, pp. 79-87, 1990 (Chinese).
[30] M. Sazid and T. N. Singh, "Numerical assessment of spacingburden ratio to effective utilization of explosive energy," International Journal of Mining Science and Technology, vol. 25, no. 2, pp. 291-297, 2015.

[31] B. F. Li and C. B. Qi, "Shaped crack mechanism and parameters design of pre-splitting blasting," West-China Exploration Engineering, no. 3, pp. 78-79, 2000 (Chinese).

[32] Q. Zong, “Theoretical analysis of charge structure's influence on pressure on bore wall," Mining and Metallurgical Engineering, vol. 26, no. 5, pp. 9-12, 2006 (Chinese).

[33] K. S. Ge, Study on Parameter of Pre-Splitting Blasting, China University of Geosciences, Beijing, China, 2009.

[34] J. G. Wang, L. F. Luan, Z. Y. Zhang, X. L. Li, and C. L. Fan, "Numerical simulation of blasting vibration effect on stability of high-steep slope," Blasting, vol. 29, no. 3, pp. 119-122, 2012. 


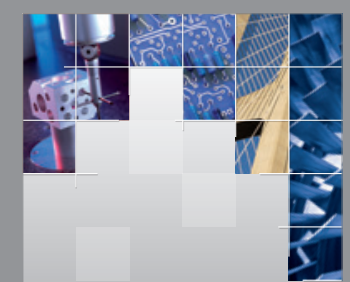

\section{Enfincering}
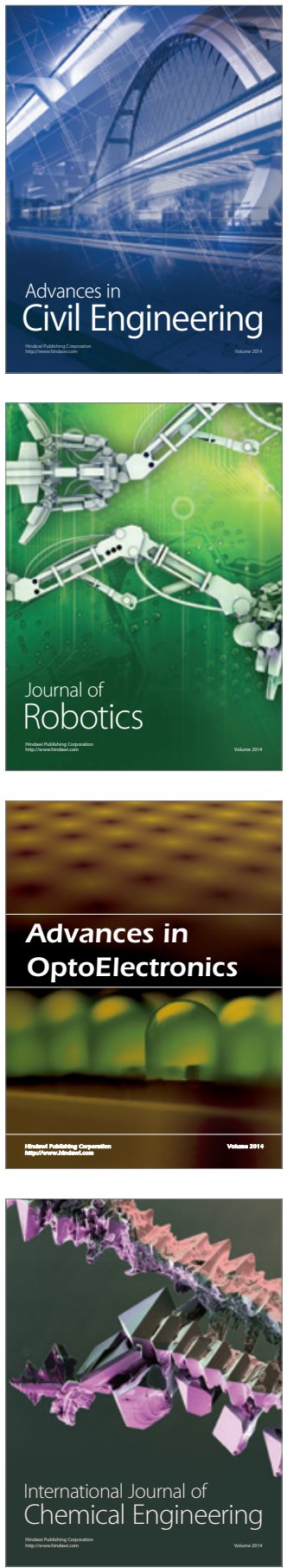

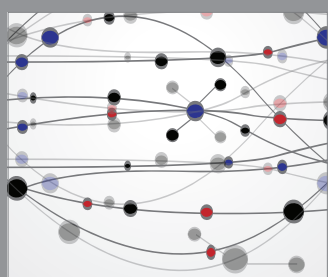

The Scientific World Journal

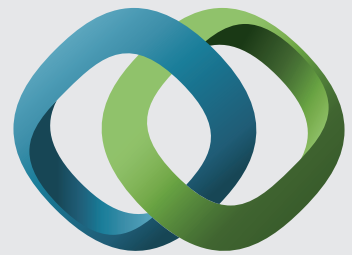

\section{Hindawi}

Submit your manuscripts at

http://www.hindawi.com
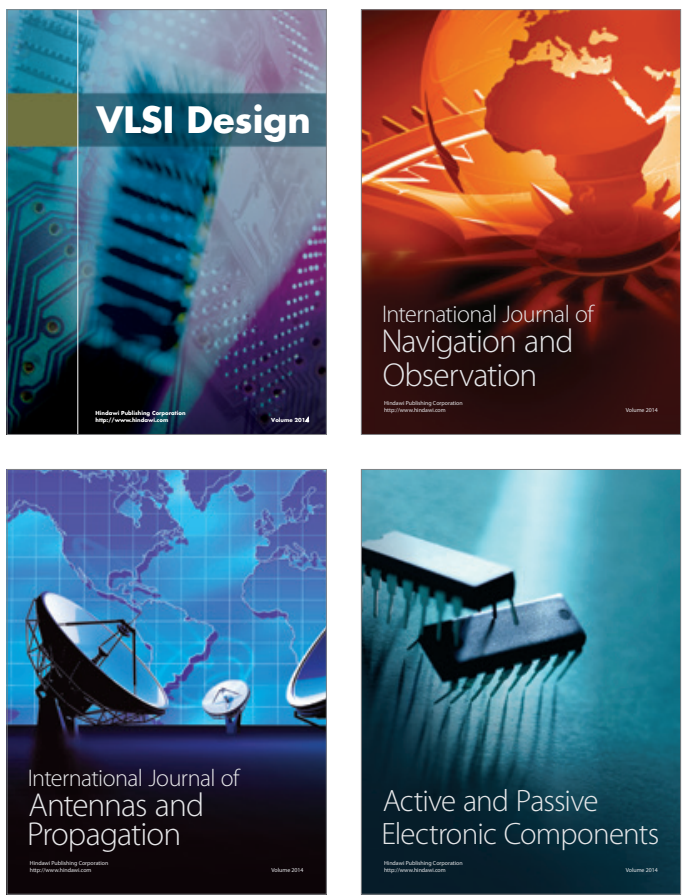
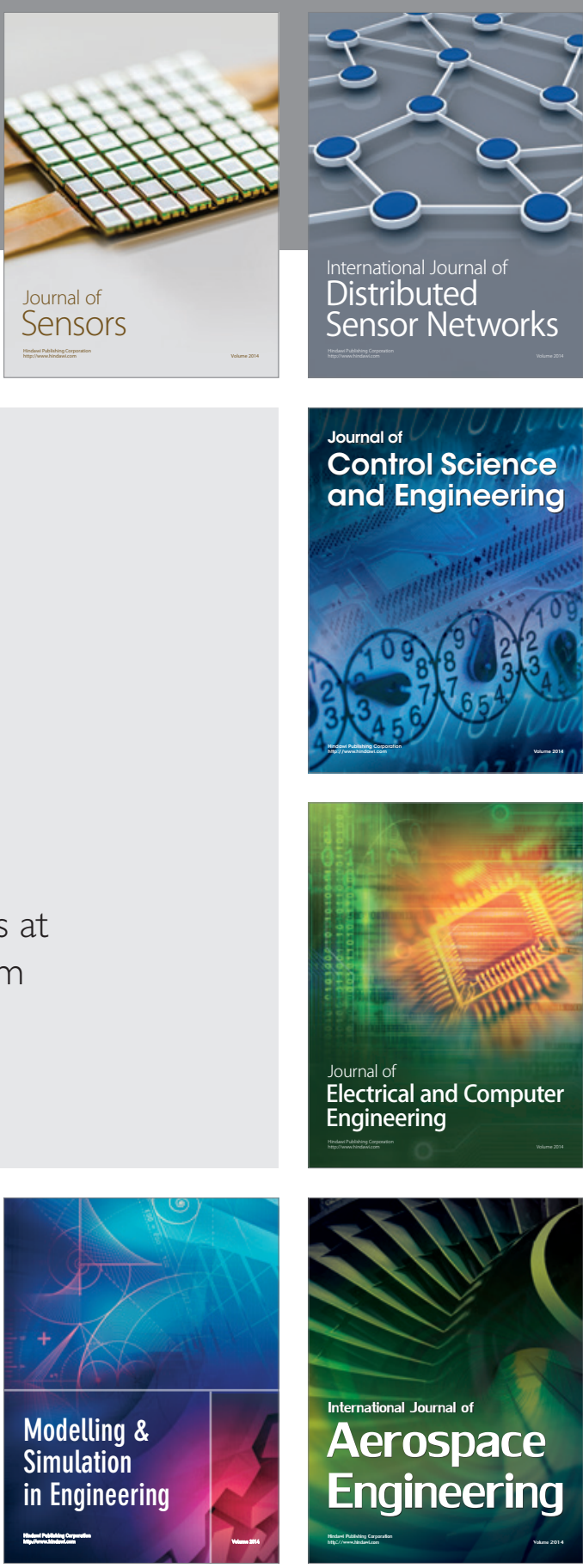

International Journal of

Distributed

Sensor Networks

Journal of

Control Science

and Engineering
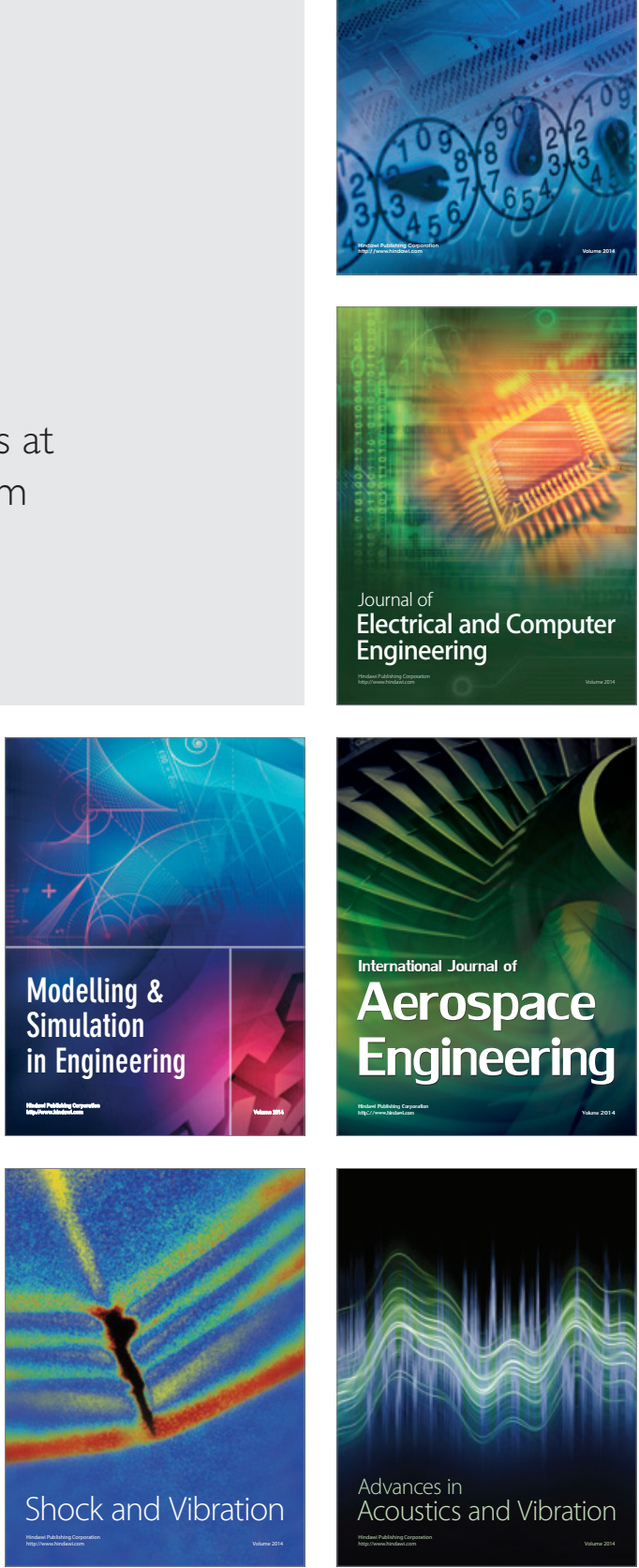